\title{
Appropriateness of antibiotic treatment in intravenous drug users, a retrospective analysis Dominik Mertz $^{\dagger 1}$, Nina Viktorin ${ }^{\dagger 1}$, Marcel Wolbers ${ }^{2}$, Gerd Laifer ${ }^{1}$, Bernd Leimenstoll ${ }^{3}$, Ursula Fluckiger ${ }^{1}$ and Manuel Battegay*1
}

\author{
Address: ${ }^{1}$ Division of Infectious Diseases \& Hospital Epidemiology, University Hospital Basel, Switzerland, ${ }^{2}$ Basel Institute for Clinical \\ Epidemiology, University Hospital Basel, Switzerland and ${ }^{3}$ Division of Internal Medicine, University Hospital Basel, Switzerland \\ Email: Dominik Mertz - mertzd@uhbs.ch; Nina Viktorin - msnina78@hotmail.com; Marcel Wolbers - wolbersm@uhbs.ch; \\ Gerd Laifer - laiferg@uhbs.ch; Bernd Leimenstoll - leimenstollb@uhbs.ch; Ursula Fluckiger - flueckigeru@uhbs.ch; \\ Manuel Battegay* - battegaym@uhbs.ch \\ * Corresponding author †Equal contributors
}

Published: 3 April 2008

BMC Infectious Diseases 2008, 8:42 doi:10.1/86//47/-2334-8-42
Received: 16 August 2007

Accepted: 3 April 2008

This article is available from: http://www.biomedcentral.com/I47I-2334/8/42

(c) 2008 Mertz et al; licensee BioMed Central Ltd.

This is an Open Access article distributed under the terms of the Creative Commons Attribution License (http://creativecommons.org/licenses/by/2.0), which permits unrestricted use, distribution, and reproduction in any medium, provided the original work is properly cited.

\begin{abstract}
Background: Infectious disease is often the reason for intravenous drug users being seen in a clinical setting. The objective of this study was to evaluate the appropriateness of treatment and outcomes for this patient population in a hospital setting.
\end{abstract}

Methods: Retrospective study of all intravenous drug users hospitalized for treatment of infectious diseases and seen by infectious diseases specialists I/200I-I2/2006 at a university hospital. Treatment was administered according to guidelines when possible or to alternative treatment program in case of patients for whom adherence to standard protocols was not possible. Outcomes were defined with respect to appropriateness of treatment, hospital readmission, relapse and mortality rates. For statistical analysis adjustment for multiple hospitalizations of individual patients was made by using a generalized estimating equation.

Results: The total number of hospitalizations for infectious diseases was 344 among 216 intravenous drug users. Skin and soft tissue infections $(n=129,37.5 \%$ of hospitalizations), pneumonia $(n=75,21.8 \%)$ and endocarditis $(n=54,15.7 \%)$ were most prevalent. Multiple infections were present in $25 \%$. Treatment was according to standard guidelines for $78.5 \%$, according to an alternative recommended program for $1 \mathrm{I} .3 \%$, and not according to guidelines or by the infectious diseases specialist advice for $10.2 \%$ of hospitalizations. Psychiatric disorders had a significant negative impact on compliance (compliance problems in $19.8 \%$ of hospitalizations) in multiple logistic regression analysis $(\mathrm{OR}=2.4, \mathrm{Cl} I . \mathrm{I}-5 . \mathrm{I}, \mathrm{p}=0.03)$. The overall readmission rate and relapse rate within 30 days was $13.7 \%$ and $3.8 \%$, respectively. Both non-compliant patient behavior $(O R=3.7, \mathrm{Cl} \mathrm{I.3-10.8,} \mathrm{P}=0.02)$ and non-adherence to treatment guidelines $(O R=3.3$, $\mathrm{Cl}$ I.I-9.7, $\mathrm{p}=0.03$ ) were associated with a significant increase in the relapse rate in univariate analysis. In 590 person-years of follow-up, $24.6 \%$ of the patients died: $6.4 \%$ died during hospitalization (1.2\% infection-related) and $13.6 \%$ of patients died after discharge.

Conclusion: Appropriate antibiotic therapy according to standard guidelines in hospitalized intravenous drug users is generally practicable and successful. In a minority alternative treatments may be indicated, although associated with a higher risk of relapse. 


\section{Background}

Infectious diseases are a major cause of morbidity and mortality among intravenous drug users (IVDU) [1-8]. Malnutrition, immunodeficiency, homelessness, and needle-sharing contribute to a high infection rate in these patients $[7,9]$. Thus, reducing these risk factors and providing adequate medical care are important aims of opioid maintenance programs $[10,11]$. In general, IVDU seek medical treatment in emergency departments more often and also need to be hospitalized more often than patients in an age-matched non-IVDU population $[4,10]$. They also tend to seek medical attention late in the course of a disease [4]. The resulting delay in diagnosis and possibly reduced number of available therapeutic options may produce a less favorable outcome to treatment as well as more frequent and potentially life-threatening complications.

Non-adherence to treatment protocols is a frequent and persistent problem in hospitalized IVDU [12]. Therefore, there may be a perception among health care workers that IVDU will be less willing to consent to or follow a specific antibiotic therapy. Such a perception might lead them to prescribe a less than optimum treatment program because the preferred protocol would be difficult for the patient to follow correctly.

Psychiatric co-morbidities in IVDU are reported in up to $30 \%$ of IVDU and are recognized as risk factors for needlesharing, more frequent sex for money or gifts and being raped [13], all of which can lead to infection. Patients with psychiatric diseases are known to have a limited capacity to consent to proposed interventions and are consequently more likely to refuse treatment [14]. Psychiatric disease as well as intravenous drug use are known risk factors for patients leaving the hospital against medical advice and for not adhering to treatment protocols [15].

Data is still scarce about success rates for treatment of infectious disease in IVDU in a hospital setting, including the extent of non-compliant patient behavior and its impact on the efficacy of treatment and patient outcomes. Therefore, the goal of the present study was to analyze the appropriateness of treatment protocols, compliance with treatment by patients, and the outcomes of therapy in IVDU who were hospitalized with infectious diseases and were seen by a specialist in infectious diseases. The hypothesis was that the appropriateness of treatment protocols in IVDU was higher than suspected by most physicians and that the outcome of treatment depends on the appropriateness of treatment and the compliance of the patients.

\section{Methods \\ Study design}

This was a retrospective study of all IVDU who were hospitalized for treatment of infectious diseases and were evaluated on demand by the infectious disease service over six years, January 2001 through December 2006, in the University Hospital Basel in Switzerland, a 780-bed primary and tertiary care center with approximately 27,000 admissions annually.

One single investigator extracted the following data from hospital charts as well as from the separate medical charts of the infectious disease specialists who were consulted: Name; gender; date of birth; date of admission; duration of hospitalization; date of infectious disease specialist consultations; duration of illicit drug use and which substances used; participation in an opioid maintenance program; main diagnosis and co morbidities; body mass index; infectious diseases diagnosis; main pathogen; additional pathogens; antibiotics, doses, application forms and durations of treatment; complications (i.e. acute renal failure, adult respiratory distress syndrome, disseminated intravasal coagulation, septic shock); admission to intensive care unit (ICU) and days on ICU; fatalities and reasons of death; fever, c-reactive protein and leucocytes at time of admission and time of discharge; time to defeverescence; readmission and reason for readmission. The data was entered in a database (SPSS 14, SPSS Inc., Chicago US), controlled by a second investigator and checked for plausibility during analysis of the dataset by another two independent reviewers.

Treatment protocols were evaluated with respect to their appropriateness for treating the diagnosed infection. Where treatment programs deviated from accepted standards, the reason for the use of an alternative program was noted. Participation in any program of heroin or methadone substitution administered by a public organization was considered participation in an opioid maintenance program.

A patient's behavior was considered to be non-compliant if it was disruptive and violated hospital rules according to the charts, i.e., if the patient did not comply with diagnostic measures or adhere to therapeutic measures, left the hospital against medical advice, continued intravenous drug use during hospitalization, smoked in the room, or assaulted hospital staff.

The study was approved by the Ethics Committee of the Cantons Basel-Stadt and Basel-Land (EKBB).

\section{Outcome parameters}

The outcome parameters were the appropriateness of the prescribed therapy (the choice of treatment and the dura- 
tion of treatment with respect to standard guidelines for treating specific infectious diseases), the readmission rate (overall rate and the rate due to relapse), in-hospital mortality (both infectious-disease related and non-infectiousdisease related), and outpatient mortality (death registries for the Canton Basel-Stadt).

Relapse was defined as infection by the same microorganism(s) responsible for the initial infection at the same site within 30 days after the patient was discharged from the hospital. For osteomyelitis, the time limit for relapse was extended to twelve months.

\section{Standards of diagnosis}

Briefly, the most important definitions were: skin and soft tissue infections according to the practice guidelines of the Infectious Diseases Society of America [16]; pneumonia according to the European guidelines [17]; endocarditis according to the Dukes criteria [18]; septic thrombosis was defined by positive blood cultures and the detection of a thrombus in imaging $[19,20]$, Finally, sepsis was defined by an infection and two or more SIRS (systemic inflammatory response syndrome) criteria [21]. Other diagnoses of infectious diseases were according to the Centers for Disease Control and Prevention (CDC) guidelines [22].

Major psychiatric disease, defined as major depression, schizophrenia, or personality disorders, was noted if mentioned in the final medical report as assed by a board certified psychiatrist.

Complications were defined as non-compliant patient behavior, renal failure, septic shock, or admission to the intensive care unit (ICU) during hospitalization.

\section{Standards of treatment}

The appropriateness of the prescribed therapy was evaluated according to written internal guidelines of the infectious diseases division, which are closely adapted from international guidelines (The Sanford Guide To Antimicrobial Therapy 2007, $[16,17,23,24])$. Antibiotic therapy for septic thrombosis is based on expert opinions [23]. In our study, therapy for septic thrombosis was defined as adequate if a minimum duration of four weeks of treatment was planned and the antibiotic was given intravenously for the first 2 weeks [20] according to the guidelines for treating right heart endocarditis $[24,25]$.

The appropriateness of treatment was analyzed by at least two investigators, which were not informed about the outcome of the cases at time of analysis. If there was no agreement, a third investigator was consulted. Whenever a pathogen was isolated, antibiotic susceptibility testing was considered for treatment. Our laboratories are work- ing according to Clinical and Laboratory Standards Institute (CLSI) guidelines.

\section{Statistical analysis}

A multiple logistic regression model was used to describe the dependence of patient compliance and in-hospital mortality on covariates, which were chosen according to clinical concerns. Adjustment for multiple hospitalizations of individual patients was made by using a generalized estimating equation (GEE) approach. Parameters were first estimated by using ordinary logistic regression, ignoring correlations between different hospitalization periods for a single patient (under "working independence"). Standard errors were then adjusted for repeat hospitalizations by using a robust sandwich estimator. The same statistical approach was used for univariate analyses. Results are given as odds ratio (OR) and 95\% confidence interval (CI).

\section{Results}

\section{Study population}

During six years, between January 2001 and December 2006, there were 2002 hospitalizations of IVDU (Figure 1). In 420 of these hospitalizations, a specialist in infectious diseases was consulted. Of these 420 cases, 76 (18.1\%) were excluded from the study. Demographic data and laboratory results for the 344 hospitalizations of 216 patients are summarized in Table 1. Although the majority of IVDU $(93.7 \%)$ were enrolled in an opioid maintenance program, $98.4 \%$ also used illicit drugs in addition to their maintenance doses. The patients in this study population suffered from diverse co-morbidities and malnutrition as indicated by the rather low body mass index.

The median time to the first consultation by an infectious diseases specialist was 2 days (range 0-92 days). In median, two consultations (range 1-10) were performed per patient.

\section{Diseases and pathogens}

The distribution of infectious diseases that were diagnosed in this population, the number of infections per hospitalization of a patient, the number of surgical interventions, and the comorbidities that were observed in the patients are summarized in Table 2. The most frequent diagnoses were skin and soft tissue infections followed by pneumonia and endocarditis. A high number of septic thromboses was diagnosed $(\mathrm{n}=36,10.5 \%)$. In addition, 23 non-septic thromboses of the deep venous system were diagnosed. Sepsis or severe sepsis due to different infections was documented in $35.5 \%(\mathrm{n}=122)$ cases, with no obvious clinical focus in $7.6 \%(\mathrm{n}=26)$. Of the 'various infections' listed in Table $1(\mathrm{n}=75,21.8 \%)$, the most frequently encountered were upper respiratory tract infections $(\mathrm{n}=12)$, infections by Candida species $(\mathrm{n}=10)$, 


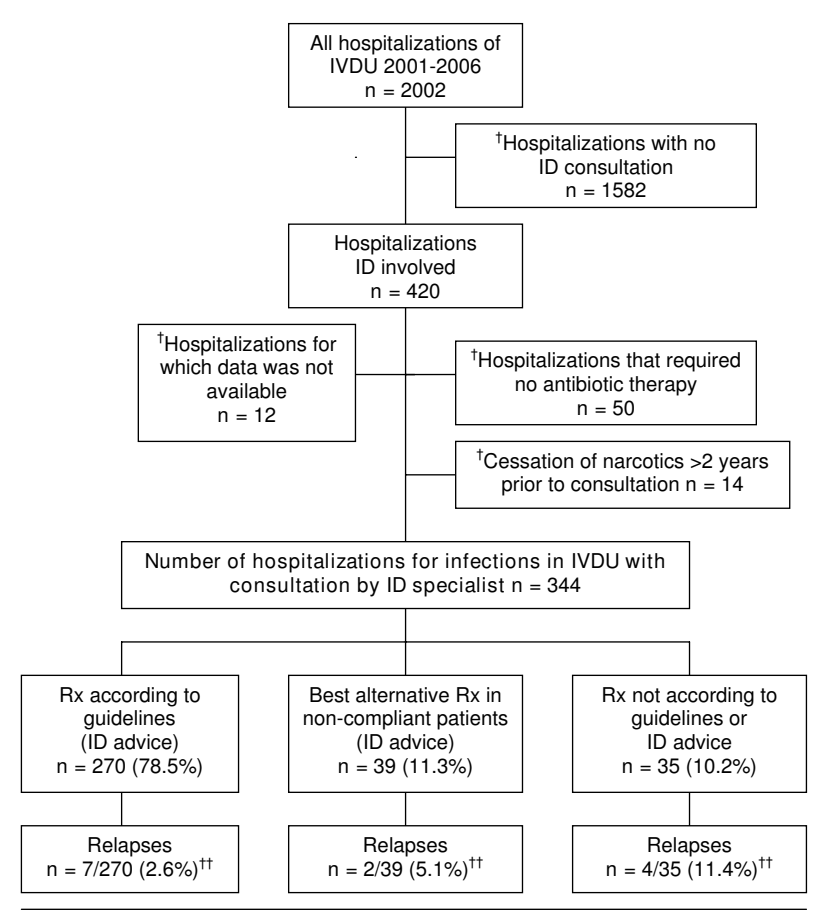

Figure I

Study population and frequency of relapses according to different treatment modalities in 344 hospitalizations among 2 I 6 IVDU*. IVDU = Intravenous drug users. $\mathrm{n}=$ Number of hospitalizations. ID = Infectious disease specialist. $\mathrm{Rx}=$ Prescribed treatment. $*$ seen by an ID during a period of 5 years. † Not included in study: -Patients who did not require antibiotic. -Former IVDU who had stopped using narcotics at least two years prior to their admittance to the hospital and were not participating in an opioid maintenance program ttp $=0.03$ ( $R x$ according to guidelines vs. others)

urinary tract infections $(\mathrm{n}=10)$, abdominal infections ( $\mathrm{n}$ $=6)$, tuberculosis $(n=5)$ and sinusitis $(n=4)$. Eighty-six $(25 \%)$ of the cases were characterized by two or more simultaneous infections. Viral co-infections, i.e., hepatitis C, HIV, and chronic hepatitis B, were common as comorbidities. Like IVDU in an earlier study $[11,26]$, close to $80 \%$ of the patients in this study were positive for hepatitis $\mathrm{C}$.

Overall, a pathogen could be isolated in $78.8 \%$ of the cases (Table 3 ). The percentage of microbiologically documented infections was $100 \%$ for bacterial endocarditis and septic thrombosis, $96 \%$ for bone and joint infections, $85.7 \%$ for primary sepsis without focus, $77.7 \%$ for skin and soft tissue infections, and $72 \%$ for pneumonia. The percentage of microbiologically documented infections for all other types of infections together was $62.3 \%$.

S. aureus was the most frequently isolated pathogen, followed by beta-hemolytic and viridans streptococci (Table
3). S.aureus was the most frequent pathogen isolated in all categories of infections: endocarditis (76\% of cases with a primary pathogen identified), bone and joint infections (58\%), primary sepsis $(57 \%)$, septic thrombosis $(56 \%)$, skin and soft tissue infections (45\%), pneumonia (35\%) and in other infections (35\%). Polymicrobial infections were observed in $18.6 \%$ of cases.

\section{Therapy and outcome}

A beta-lactam antibiotic, most frequently amoxicilline/ clavulanate, was used for treatment in $84.9 \%$ of the cases (Table 3 ). The median duration of intravenous and oral antibiotic therapy was 12 days (range 0-117 days) and 1 day (range 0-36 days), respectively.

Treatment according to standard guidelines was possible in 270 (78.5\%) of the 344 hospitalizations. A best alternative therapy was prescribed as recommended by an infectious disease specialist for non-compliant patients in $39(11.3 \%)$ cases. Therapy that was not according to an infectious disease specialist advice was prescribed in 35 (10.2\%) cases (Figure 1).

For some infections, e.g., for skin and soft tissue infections, sepsis, or pneumonia, $47.1 \%$ of the cases were scheduled for additional outpatient therapy after an adequate or best alternative in-hospital course of treatment (Table 4 ). In $12.2 \%$ of the hospitalizations, patients were discharged against medical advice either with or without therapy.

Complications occurred in 153 hospitalizations (44.5\%). Complications noted were acute renal failure (8.4\%) and septic shock (3.2\%). In $21.5 \%$ of the hospitalizations, the patients were admitted to the ICU (median length of ICU stay $=3$ days $)$. The presence of pneumonia or endocarditis most often led to ICU admission-36\% of all cases of pneumonia and $29.6 \%$ of all cases of endocarditis. Noncompliant patient behavior was the most frequent complication (19.8\%), and a multiple logistic regression analysis (Table 5) revealed a significant association of noncompliance with psychiatric disorders (OR = 2.4, CI 1.15.1, $\mathrm{p}=0.03$ ). In hospitalizations of non-compliant patients, the patient was able to follow the prescribed therapeutic program in accordance with standard guidelines in $27.9 \%$ of the cases.

The overall 30-day readmission rate was $13.7 \%$ (Table 4 ). Among readmitted cases, $27.7 \%$ had a relapse (overall relapse rate $3.8 \%$ ). The highest relapse rates occurred with septic thrombosis (5.6\%) and endocarditis (3.7\%). Both non-compliant patient behavior $(\mathrm{OR}=3.7$, CI 1.3-10.8, p $=0.02)$ and non-adherence to treatment guidelines $(\mathrm{OR}=$ 3.3 , CI $1.1-9.7, \mathrm{p}=0.03$ ) were associated with a significant increase in the relapse rate in univariate analysis. 
Table I: Patient characteristics of 344 hospitalizations among 2 I 6 IVDU*

\begin{tabular}{|c|c|c|c|}
\hline & & & $\%$ \\
\hline Gender (male/female) $(n=344)$ & & & $67 / 33$ \\
\hline \multicolumn{4}{|c|}{ Participation in opioid maintenance program (information available in $n=270$ ) } \\
\hline In a program $=253$ & & & 93.7 \\
\hline \multirow[t]{2}{*}{ No program $=17$} & & & 6.3 \\
\hline & & median & (range) \\
\hline Age (years) & $(n=344)$ & 38 & $(18-58)$ \\
\hline Body mass index $\left(\mathrm{kg} / \mathrm{m}^{2}\right)$ & $(n=212)$ & 20.9 & $(14-40)$ \\
\hline Temperature at admission $\left({ }^{\circ} \mathrm{C}\right)$ & $(n=328)$ & 38.6 & $(35.3-42)$ \\
\hline C-reactive protein at admission $(\mathrm{mg} / \mathrm{l})$ & $(n=342)$ & 121.5 & $(0.7-5 \mid 4)$ \\
\hline White blood cell count $(\times 109 / 1)$ & $(n=342)$ & 10.9 & $(0.1-80.4)$ \\
\hline Length of hospital stay (days) & $(n=344)$ & 17 & $(1-125)$ \\
\hline
\end{tabular}

* seen by an ID during a period of 5 years.

tData on opioid substitution program participation, body mass index, temperature, white cell count, and C-reactive protein was not available for all patients.

IVDU = Intravenous drug user.

$\mathrm{n}=$ Total number of hospitalizations for which specific data was available. (Total number of hospitalizations in this study $=344$.).

$\mathrm{ID}=$ Infectious disease specialist

Because of the low number of relapses, no multiple (adjusted) logistic models were performed.

Overall in-hospital mortality was $6.4 \%(\mathrm{n}=22$, Table 4$)$. The highest mortality rates were associated with bacterial endocarditis (13\%), pneumonia (12\%), and sepsis
(9.6\%). The age of the patient was the only independent risk factors for infection-related, in-hospital mortality (Table 5). State death record information was available for 199 (92.1\%) of the 216 patients, which allowed the evaluation of mortality rates after discharge from the hospital (a total of 590 person-years of follow-up). The

Table 2: Infectious disease diagnoses and co-morbidities in 344 hospitalizations among 2 I6 IVDU*

\begin{tabular}{|c|c|}
\hline & n (\%) \\
\hline \multicolumn{2}{|l|}{ Types of infectious disease diagnosest: } \\
\hline Skin and soft tissue infection & $129(37.5)$ \\
\hline Pneumonia & $75(21.8)$ \\
\hline Endocarditis & $54(15.7)$ \\
\hline Bone and joint infections & $50(14.5)$ \\
\hline Septic thrombosis & $36(10.5)$ \\
\hline Primary sepsis without focus & $26(7.6)$ \\
\hline Various infections & $75(21.8)$ \\
\hline \multicolumn{2}{|l|}{ Number of simultaneous infections: } \\
\hline one infection & $258(75.0)$ \\
\hline two infections & $70(20.3)$ \\
\hline three or more infections & $16(4.7)$ \\
\hline Number of hospitalizations where surgical intervention was required & $110(32.0)$ \\
\hline \multicolumn{2}{|l|}{ Comorbiditiest: } \\
\hline Major psychiatric disease & $52(15.1)$ \\
\hline Alcohol addiction & $55(16.0)$ \\
\hline Nicotin addiction & $265(77.0)$ \\
\hline HIV infection & $120(34.9)$ \\
\hline Chronic hepatitis B & 47 (I3.7) \\
\hline Hepatitis C & $268(77.9)$ \\
\hline Anemia & $157(45.5)$ \\
\hline Deep venous thrombosis (non-septic) & $23(6.7)$ \\
\hline
\end{tabular}

IVDU = Intravenous drug users.

* seen by an ID during a period of 5 years.

† 447 diagnoses among 344 hospital episodes. During one hospital episode more than one diagnosis and comorbidity can be documented 
Table 3: Pathogens identified and antibiotic therapies used in 344 hospitalizations among 216 IVDU*

n (\%)

\begin{tabular}{lc}
\hline Pathogens & \\
Staphylococcus aureus & 131 I $(38.1)$ \\
Beta-hemolytic streptococci & $42(12.2)$ \\
Viridans streptococci & $30(8.7)$ \\
Enterobacteriaceae & $17(4.9)$ \\
Streptococcus pneumoniae & $14(4.1)$ \\
Pseudomonas aeruginosa & $10(2.9)$ \\
Coagulase-negative staphylococci & $6(1.7)$ \\
Mycobacteria spp. & $6(1.7)$ \\
Other pathogens & $15(4.4)$ \\
Polymicrobial infections & $64(18.6)$ \\
No pathogen identified & $73(21.2)$ \\
\hline Therapy ${ }^{\dagger}$ & \\
Beta-lactams & \\
Amoxicilline/Clavulanate & $292(84.9)$ \\
Penicilline & $129(37.5)$ \\
Flucloxacilline & $54(15.7)$ \\
Cephalosporines & $48(14.0)$ \\
Piperacilline/Tazobactam & $33(9.6)$ \\
Carbapenemes & $18(5.2)$ \\
Non-beta-lactams & $10(2.9)$ \\
Aminoglycosides (used in combination) & \\
Fluoroquinolones & $10(2.9)$ \\
Antituberculosis drugs & $8(2.3)$ \\
Others & $6(1.7)$ \\
& $28(8.1)$ \\
\hline
\end{tabular}

* seen by an ID during a period of 5 years.

† Antibiotic prescribed for the longest period intravenously during one hospitalization.

₹ Two of I3I (I.53\%) S.aureus infections were due to methicillinresistant S.aureus (MRSA).

median observation time was 35.6 months (range 1.673.9 months). A total of 49 (24.6\%) patients died during the observation period. Of these 49 patients, 27 (55.1\%) died after discharge from the hospital, 3 of them within 30 days ( 2 for whom death was possibly infection related, 1 who died of a trauma). The remaining 24 deaths occurred more than 30 days after the last date of discharge (median 232 days).

There was no significant difference in non-compliant behavior, relapse- or readmission rate between HIVinfected and HIV-negative patients. The association between infection-related deaths and HIV status during hospitalization was non-significant $(\mathrm{OR}=1.9$, CI 0.8-4.9, $\mathrm{p}=0.161)$. Overall in hospital mortality $(\mathrm{OR}=2.4$, CI 1.0-5.6, $\mathrm{p}=0.06$ ) and mortality in the follow up period $(\mathrm{OR}=2.4$, CI 1.3-4.4, $\mathrm{p}=0.006)$ was increased for episodes with HIV-infected patients.

\section{Discussion}

This study investigating 344 hospitalizations in 216 IVDU demonstrates that the vast majority of infectious disease episodes in these patients can be treated successfully by following international guidelines or protocols adapted from these standard guidelines.

Treatment according to guidelines was completed in 78\% of hospitalizations, and treatment with a best alternative regimen recommended by a specialist in infectious diseases was possible in an additional $11 \%$ of patients who had been identified as non-compliant (Figure 1). Hence, even complex and prolonged intravenous antibiotic treatment can be administered successfully in almost $90 \%$ of IVDU. Prescription of alternative treatment programs and non-adherence by patients were associated with a twofold and fourfold increase in the relapse rate, respectively. However, when the recommendations of an infectious disease specialist were followed, relapse occurred in only $2.6 \%$ of the cases (Figure 1). Physicians should be aware that deviating from recommended protocols is associated with a higher rate of treatment failure and relapse. Making compromises in treatment strategies cannot be justified on the basis of a belief that a patient may not adhere to the prescribed program. In an earlier study of HIV-infected patients, it was demonstrated that IVDU also are at risk of receiving inadequate treatment for $\mathrm{HIV}$, in part because physicians did not follow the treatment programs that were recommended by infectious disease specialists [27].

The extent of adherence to recommended treatment programs for infections in IVDU and its relationship to treatment outcome had not been analyzed prior to this study. Self-reported, non-adherence to therapy is a problem for IVDU who are being treated for infectious diseases, just as it is for IVDU who are receiving antiretroviral therapy [28]. Therefore, a patient's adherence to a program of taking oral antibiotics after the patient has been discharged from the hospital cannot be taken for granted. The high rate $(>90 \%)$ of IVDU who were participating in a structured opioid maintenance program may partially explain the high rate of adherence to treatment programs by patients in the study population, even though almost all patients reported using illicit drugs in addition to their official maintenance drug dose, which points to their severe addiction.

Major psychiatric disorders were associated with a reduced adherence in our study, which confirms other reports in the literature that describe the more risky behaviors encountered in these patients [13]. Gender, age, alcohol addiction, and HIV infection had no significant impact on patient compliance in a multivariate analysis (Table 5).

The mortality rate for IVDU is known to be greater than that of the general population [29]. In our study population, in-hospital mortality (6.4\%) was rather low (Table 
Table 4: Discharge data for 344 hospitalizations among 216 IVDU* for treatment of infectious diseases

\begin{tabular}{|c|c|}
\hline & n (\%) \\
\hline Discharge with oral antibiotics after adequate or best alternative therapy & $162(47.1)$ \\
\hline Discharge without antibiotics after adequate or best alternative therapy & $117(34.0)$ \\
\hline Discharge against medical advice, with oral antibiotics & $29(8.4)$ \\
\hline Discharge against medical advice, without antibiotic therapy & $13(3.8)$ \\
\hline Discharge without available follow-up data for antibiotic therapy & $\mathrm{I}(0.3)$ \\
\hline In-hospital deathst & $22(6.4)$ \\
\hline Total & $344(100)$ \\
\hline \multicolumn{2}{|l|}{ Readmissions } \\
\hline$<30$ days with relapse of original infection & $13(3.8)$ \\
\hline with infection but not relapse of original infection & $19(5.5)$ \\
\hline with no infection & $15(4.4)$ \\
\hline $30-90$ days & $53(15.4)$ \\
\hline$>90$ days & $100(29.1)$ \\
\hline Deaths overall (determined from state records for $n=199$ patients) & $49(24.6)$ \\
\hline After discharge from hospital: not related to treated infection & $27(13.6)$ \\
\hline \multicolumn{2}{|l|}{ In-hospital (of cases): } \\
\hline infection related & $18(5.2)$ \\
\hline not infection related & $4(1.2)$ \\
\hline
\end{tabular}

IVDU = Intravenous drug users.

* seen by an ID during a period of 5 years.

tDescribed in detail in the lower part of the table.

4). Most deaths during the study occurred more than 30 days after discharge from the hospital and were not related to prior hospitalization for treatment of infectious disease. Similar observations were made in a longitudinal study among opioid addicts [29]. The only independent risk factor for in-hospital death in this study was older age (Table 5). In-hospital deaths of IVDU were primarily due to uncontrolled active infections despite their receiving adequate therapy for the infections according to standard guidelines. The highest mortality rate was observed in patients with bacterial endocarditis $(13 \%)$. This rate is comparable to infection-related, in-hospital mortality rates attributable to endocarditis among in hospital patients who are not addicts (14\%; in-house, unpublished data). The data includes mortality due to both right-sided and left-sided and staphylococcal and streptococcal endocarditis. Although IVDU may not seek medical treatment until late in the course of an infectious disease and have a

Table 5: Risk factors associated with patient non-compliance and infection-related mortality (multiple logistic regression analysis) of 344 hospitalizations among 216 IVDU*

\begin{tabular}{lcc}
\hline Risk factors for patient's non-compliance & OR (95\% CI) & P-value \\
\hline Male gender & $1.2(0.6-2.2)$ & 0.60 \\
Age (per I0 years older) & $0.8(0.5-1.2)$ & 0.26 \\
Alcohol addiction & $0.8(0.4-1.7)$ & 0.55 \\
Psychiatric disorders & $2.4(1.1-5.1)$ & $0.03 \dagger$ \\
HIV infection & $0.7(0.3-1.3)$ \\
\hline Risk factors for infection-related mortality & OR (95\% CI) \\
\hline Number of infections & P-value \\
Age (per I0 years older) & $1.4(0.7-2.9)$ \\
Male gender & $2.0(1.0-3.8)$ \\
Number of comorbidities & $1.0(0.4-2.6)$ & 0.32 \\
\end{tabular}

* seen by an ID during a period of 5 years.

† Statistical significance $(p<0.05)$. 
greater number of co-morbidities and complications, they tend to be younger and have a predominant involvement of the tricuspid valve [30]. Both factors contribute to a lower mortality compared to the $20-25 \%$ mortality in staphylococcal endocarditis of the left heart [24,31-33].

Our study corroborates results from earlier studies $[1,2,34]$ that show that skin and soft tissue infections are the most frequently occurring infections in IVDU (Table 2 ). In about half the cases of skin and soft tissue infection, surgical intervention was implemented in addition to antibiotic therapy. The duration of intravenous antibiotic therapy is quite short for skin and soft tissue infections, which may partly explain the high rate of adherence to our guidelines.

The majority (36 of 59) of deep venous thromboses in IVDU was septic, constituting $10.5 \%$ of hospitalizations. These results emphasize the importance of screening for signs and symptoms of deep venous thrombosis in IVDU.

In almost $80 \%$ of the hospitalizations, the causative pathogen for the infection could be identified. The predominance of $S$. aureus and streptococci (Table 3) confirms earlier results [5,6,31,35-38]. Methicillin-resistant $S$. aureus (MRSA) may lead to outbreaks of infection among IVDU [39,40], although in our study, MRSA was isolated to only two cases-both in the same patient, which confirms the low prevalence of MRSA in our region [41,42]. Amoxicilline/clavulanate was the antibiotic used most frequently to treat infections (Table 3 ), which is comparable to results in other studies, e.g., a similar study conducted in the emergency department of the University Hospital Basel studying the general patient population [43].

The main limitation of this study is its retrospective character. The source of our data was restricted to hospital medical records and the detailed records of the specialists in the infectious diseases department. A second limitation is that detailed information about the duration of drug addiction in patients was missing in most cases. Therefore, we were not able to substantiate the impression that the risk for hospitalization due to infections increased with the number of years of addiction. Nevertheless, the age of our study population is rather high (median 38 years, mean 37 years) in comparison with the mean age of IVDU in a Swiss heroin maintenance program (mean 20.2-27 years, depending on the addictive drug that was being used, 2001) [44]. Hence, younger patients were underrepresented in hospitalized IVDU in our study. Only in part, this can be explained by the increasing mean age of IVDU over time as shown in the US recently [45]. A third limitation is the fact that co-morbidities could not be investigated in detail, for example, the fact that there was no reference to co-morbidity in a patient's final med- ical report does not completely exclude the possibility of co-morbidity having existed and we were not able to standardize the assessment of non-compliant behavior. As fourth limitation, we analyzed only hospitalization seen by infectious disease specialists and a generalization to all IVDU hospitalizations may be limited. Nevertheless, we assume that we were consulted for the more difficult situations rather enforcing the good appropriateness.

The strength of this study was the high number of hospitalizations that were investigated in a population of IVDU. Although this study was a retrospective investigation, we were able to extract significant information from the general medical charts and from the detailed reports of the infectious disease specialists by using a sophisticated case report form that included precise definitions of different infectious diseases. Also, our outcomes were validated by the state death records, which confirmed the favorable outcome in most patients.

\section{Conclusion}

Appropriate antibiotic therapy in hospitalized IVDU is generally practicable and successful. In a minority of cases, alternative treatments may be indicated, although they are associated with a higher risk of failure. Complicated disease courses and readmissions are common in IVDU; but in this study, only a small percentage of readmissions were due to relapse. Overall mortality in this population of IVDU is high, but it does not appear to be related to prior hospitalizations for infectious disease.

\section{Competing interests}

The author(s) declare that they have no competing interests.

\section{Authors' contributions}

$\mathrm{DM}, \mathrm{UF}$ and MB designed the study, supervised the data collection and interpreted the analyses. NV and DM collected and analysed data and drafted the first manuscript. GL and BL acquired data. DM and MW performed the statistical analysis. All authors critically revised the final draft of the manuscript.

\section{Acknowledgements}

The authors thank André Haefeli for support of data acquisition and Sigrid Strom, Seattle, for valuable assistance to edit the manuscript. Further, the authors thank Andreas F. Widmer and R. Frei for their helpful comments.

We kindly thank the Margarete and Walter Lichtenstein Foundation for supporting Nina Viktorin with an unrestricted educational grant. In part, the "Stiftung Forschung Infektionskrankheiten" supported the study with an unrestricted grant. All other authors: no financial support.

\section{References}

I. Bassetti S, Hoffmann M, Bucher HC, Fluckiger U, Battegay M: Infections requiring hospitalization of injection drug users who 
participated in an injection opiate maintenance program. Clin Infect Dis 2002, 34(5):7II-7I3.

2. Binswanger IA, Kral AH, Bluthenthal RN, Rybold DJ, Edlin BR: High prevalence of abscesses and cellulitis among communityrecruited injection drug users in San Francisco. Clin Infect Dis 2000, 30(3):579-58I.

3. Scheidegger C, Zimmerli W: Infectious complications in drug addicts: seven-year review of 269 hospitalized narcotics abusers in Switzerland. Reviews of infectious diseases 1989, I I(3):486-493.

4. Palepu A, Tyndall MW, Leon H, Muller J, O'Shaughnessy MV, Schechter MT, Anis AH: Hospital utilization and costs in a cohort of injection drug users. Cmaj 200I, 165(4):415-420.

5. Louria DB, Hensle T, Rose J: The major medical complications of heroin addiction. Annals of internal medicine 1967, 67(I): I-22.

6. Cherubin CE, Sapira JD: The medical complications of drug addiction and the medical assessment of the intravenous drug user: 25 years later. Annals of internal medicine 1993, I I9(10): 1017-1028.

7. Gordon RJ, Lowy FD: Bacterial infections in drug users. The New England journal of medicine 2005, 353(18): 1945-1954.

8. Hind CR: Pulmonary complications of intravenous drug misuse. 2. Infective and HIV related complications. Thorax 1990, 45( I2):957-96I.

9. Murphy EL, DeVita D, Liu H, Vittinghoff E, Leung P, Ciccarone DH, Edlin BR: Risk factors for skin and soft-tissue abscesses among injection drug users: a case-control study. Clin Infect Dis 200I, 33(I):35-40.

10. Stein MD, Anderson B: Injection frequency mediates health service use among persons with a history of drug injection. Drug and alcohol dependence 2003, 70(2): $159-168$.

II. Sendi P, Hoffmann M, Bucher HC, Erb P, Haller P, Gyr N, Battegay M: Intravenous opiate maintenance in a cohort of injecting drug addicts. Drug and alcohol dependence 2003, 69(2): $183-188$.

12. Dans PE, Matricciani RM, Otter SE, Reuland DS: Intravenous drug abuse and one academic health center. Jama 1990, 263(23):3|73-3|76.

13. Dausey DJ, Desai RA: Psychiatric comorbidity and the prevalence of HIV infection in a sample of patients in treatment for substance abuse. The Journal of nervous and mental disease 2003, I9I(I): I0-17.

14. Jacob R, Clare IC, Holland A, Watson PC, Maimaris C, Gunn M: Selfharm, capacity, and refusal of treatment: implications for emergency medical practice. A prospective observational study. Emerg Med J 2005, 22(I I):799-802.

15. Seaborn Moyse H, Osmun WE: Discharges against medical advice: a community hospital's experience. Can J Rural Med 2004, 9(3): | 48-153.

16. Stevens DL, Bisno AL, Chambers HF, Everett ED, Dellinger P, Goldstein EJ, Gorbach SL, Hirschmann JV, Kaplan EL, Montoya JG, Wade JC: Practice guidelines for the diagnosis and management of skin and soft-tissue infections. Clin Infect Dis 2005, 4I(I0): I373-I 406.

17. Woodhead M, Blasi F, Ewig S, Huchon G, leven M, Ortqvist A, Schaberg T, Torres A, van der Heijden G, Verheij TJ: Guidelines for the management of adult lower respiratory tract infections. Eur Respir J 2005, 26(6): I I38-II80.

18. Durack DT, Lukes AS, Bright DK: New criteria for diagnosis of infective endocarditis: utilization of specific echocardiographic findings. Duke Endocarditis Service. The American journal of medicine 1994, 96(3):200-209.

19. Fah F, Zimmerli W, Jordi M, Schoenenberger RA: Septic deep venous thrombosis in intravenous drug users. Swiss Med Wkly 2002, I 32(27-28):386-392.

20. Mertz D, Khanlari B, Viktorin N, Battegay M, Fluckiger U: Intravenous antibiotic treatment of less than 28 days is sufficient for suppurative thrombophlebitis in intravenous drug users. Clin Infect Dis 2008 in press.

21. Bone RC, Balk RA, Cerra FB, Dellinger RP, Fein AM, Knaus WA, Schein RM, Sibbald W]: Definitions for sepsis and organ failure and guidelines for the use of innovative therapies in sepsis. The ACCPISCCM Consensus Conference Committee. American College of Chest Physicians/Society of Critical Care Medicine. Chest 1992, I0 I(6): I644-1655.
22. Horan TC, Gaynes RP: Hospital Epidemiology and Infection Control. 3rd edition edition. Edited by: Mayhall CG. Philadelphia:Lippincott Williams \& Wilkins; 2004:1659-1702.

23. Mermel LA, Farr BM, Sherertz RJ, Raad, O'Grady N, Harris JS, Craven $D E$ : Guidelines for the management of intravascular catheter-related infections. Clin Infect Dis 200I, 32(9): I249-I272.

24. Baddour LM, Wilson WR, Bayer AS, Fowler VG Jr., Bolger AF, Levison ME, Ferrieri P, Gerber MA, Tani LY, Gewitz MH, Tong DC, Steckelberg JM, Baltimore RS, Shulman ST, Burns JC, Falace DA, Newburger JW, Pallasch TJ, Takahashi M, Taubert KA: Infective endocarditis: diagnosis, antimicrobial therapy, and management of complications: a statement for healthcare professionals from the Committee on Rheumatic Fever, Endocarditis, and Kawasaki Disease, Council on Cardiovascular Disease in the Young, and the Councils on Clinical Cardiology, Stroke, and Cardiovascular Surgery and Anesthesia, American Heart Association: endorsed by the Infectious Diseases Society of America. Circulation 2005, I I I (23):e394-434.

25. Dworkin RJ, Lee BL, Sande MA, Chambers HF: Treatment of rightsided Staphylococcus aureus endocarditis in intravenous drug users with ciprofloxacin and rifampicin. Lancet 1989 , 2(867I): $|07|-1073$.

26. Diamantis I, Bassetti S, Erb P, Ladewig D, Gyr K, Battegay M: High prevalence and coinfection rate of hepatitis $G$ and $C$ infections in intravenous drug addicts. Journal of hepatology 1997, 26(4):794-797.

27. Bassetti S, Battegay M, Furrer H, Rickenbach M, Flepp M, Kaiser L, Telenti $A$, Vernazza PL, Bernasconi $E$, Sudre $P$ : Why is highly active antiretroviral therapy (HAART) not prescribed or discontinued? Swiss HIV Cohort Study. Journal of acquired immune deficiency syndromes (1999) 1999, 2 I(2): I I4-II9.

28. Glass TR, De Geest $S$, Weber R, Vernazza PL, Rickenbach M, Furrer H, Bernasconi E, Cavassini M, Hirschel B, Battegay M, Bucher HC: Correlates of self-reported nonadherence to antiretroviral therapy in HIV-infected patients: the Swiss HIV Cohort Study. Journal of acquired immune deficiency syndromes (1999) 2006, 4 I (3):385-392.

29. Joe GW, Simpson DD: Mortality rates among opioid addicts in a longitudinal study. American journal of public health 1987, 77(3):347-348.

30. Fowler VG Jr., Miro JM, Hoen B, Cabell CH, Abrutyn E, Rubinstein E, Corey GR, Spelman D, Bradley SF, Barsic B, Pappas PA, Anstrom KJ, Wray D, Fortes CQ, Anguera I, Athan E, Jones P, van der Meer JT, Elliott TS, Levine DP, Bayer AS: Staphylococcus aureus endocarditis: a consequence of medical progress. Jama 2005, 293(24):3012-302I.

31. Hecht SR, Berger M: Right-sided endocarditis in intravenous drug users. Prognostic features in 102 episodes. Annals of internal medicine 1992, II 7(7):560-566.

32. Martin-Davila P, Navas E, Fortun J, Moya JL, Cobo J, Pintado V, Quereda C, Jimenez-Mena M, Moreno S: Analysis of mortality and risk factors associated with native valve endocarditis in drug users: the importance of vegetation size. American heart journal 2005, I 50(5): 1099-II06.

33. Ruotsalainen E, Sammalkorpi K, Laine J, Huotari K, Sarna S, Valtonen $\mathrm{V}$, Jarvinen A: Clinical manifestations and outcome in Staphylococcus aureus endocarditis among injection drug users and nonaddicts: a prospective study of 74 patients. BMC infectious diseases 2006, 6:137.

34. Bergstein JM, Baker EJ, Aprahamian C, Schein M, Wittmann DH: Soft tissue abscesses associated with parenteral drug abuse: presentation, microbiology, and treatment. The American surgeon 1995, 6 I (1 2): I105-II08.

35. Bassetti S, Battegay M: Staphylococcus aureus infections in injection drug users: risk factors and prevention strategies. Infection 2004, 32(3): 163-169.

36. Crane LR, Levine DP, Zervos MJ, Cummings G: Bacteremia in narcotic addicts at the Detroit Medical Center. I. Microbiology, epidemiology, risk factors, and empiric therapy. Reviews of infectious diseases 1986, 8(3):364-373.

37. Wilson LE, Thomas DL, Astemborski J, Freedman TL, Vlahov D: Prospective study of infective endocarditis among injection drug users. The Journal of infectious diseases 2002, 185(12): 176I-1766.

38. Summanen PH, Talan DA, Strong C, McTeague M, Bennion R, Thompson JE Jr., Vaisanen ML, Moran G, Winer M, Finegold SM: Bacteriology of skin and soft-tissue infections: comparison of 
infections in intravenous drug users and individuals with no history of intravenous drug use. Clin Infect Dis 1995, 20 Suppl 2:S279-82.

39. Fleisch F, Oechslin EC, Gujer AR, Ritzler E, Imhof A, Ruef C, Reinhart $\mathrm{WH}$ : Transregional spread of a single clone of methicillinresistant Staphylococcus aureus between groups of drug users in Switzerland. Infection 2005, 33(4):273-277.

40. Kluytmans J, van Belkum A, Verbrugh H: Nasal carriage of Staphylococcus aureus: epidemiology, underlying mechanisms, and associated risks. Clinical microbiology reviews 1997, I (3):505-520.

4I. Bassetti S, Wolfisberg L, Jaussi B, Frei R, Kuntze MF, Battegay M, Widmer AF: Carriage of Staphylococcus aureus among injection drug users: lower prevalence in an injection heroin maintenance program than in an oral methadone program. Infect Control Hosp Epidemiol 2004, 25(2): I 33-I 37.

42. Mertz D, Frei R, Jaussi B, Tietz A, Stebler C, Fluckiger U, Widmer AF: Throat swabs are necessary to reliably detect carriers of Staphylococcus aureus. Clin Infect Dis 2007, 45(4):475-477.

43. Mettler J SM Sendi P, Widmer AF, Bingisser R, Battegay M, Fluckiger $U$, Bassetti S: Empirical use of antibiotics and adjustment of empirical antibiotic therapies in a university hospital: a prospective observational study. BMC infectious diseases 2007, 7(2I):

44. Zinkernagel C, Naef MR, Bucher HC, Ladewig D, Gyr N, Battegay M: Onset and pattern of substance use in intravenous drug users of an opiate maintenance program. Drug and alcohol dependence 200I, 64(I): 105-109.

45. Armstrong GL: Injection drug users in the United States, 19792002: an aging population. Archives of internal medicine 2007, 167(2): 166-173.

\section{Pre-publication history}

The pre-publication history for this paper can be accessed here:

http://www.biomedcentral.com/1471-2334/8/42/prepub 